REOP. Vol. 14, $N^{0} 1,1^{\text {er }}$ Semestre, 2003, pp. 41-59

\title{
REFLEXIONES SOBRE EL FUTURO DE LA ORIENTACIÓN PSICOPEDAGÓGICA INMERSA EN UNA ENCRUCIJADA SOCIOCULTURAL
}

\author{
THOUGHTS ON THE FUTURE OF EDUCATIONAL AND VOCATIONAL \\ GUIDANCE WITHIN A SOCIOCULTURAL CROSSROADS
}

\author{
José Antonio Benavent Oltra* \\ Universidad de Valencia
}

\begin{abstract}
RESUMEN
Este artículo pretende hacernos reflexionar sobre el futuro de la Orientación psicopedagógica en la actual encrucijada sociocultural apuntando algunas ideas sobre su probable evolución. Invita a situarse ante el problema analizando la importancia que el nuevo campo científico de la «Prospectiva» está adquiriendo para aportar soluciones científicas a los inquietantes retos del futuro. Además, ofrece una somera imagen del estado actual de la Orientación a fin de deliberar sobre sus posibles funciones en la sociedad venidera, en relación con: la demografía (envejecimiento e inmigración poblacional); la juventud; la multiculturalidad; la tecnología; la escuela (especialización, prevención y reforma); el mundo del trabajo y sus tendencias emergentes y, finalmente, sobre la probable evolución de los actuales modelos de orientación. Aunque las grandes interrogantes planteadas quedan abiertas, se ofrecen interesantes sugerencias al respecto. Sugerencias que tratan de ayudarnos a reflexionar y a dilucidar propuestas creativas sobre nuestro futuro profesional.
\end{abstract}

Palabras clave: Perspectivas de la Orientación psicopedagógica. Visión prospectiva. Modelos de Orientación.

\section{ABSTRACT}

This paper tries to make us reflect on the future of Educational and Vocational Guidance within the current sociocultural crossroads and suggests some ideas about its possible evolution. It encourages us to face the problem and analyzes the importance that the new scientific field of «Prospective» is gaining in order to provide scientific solutions to the uncertain future challenges. An overview image of

* José Antonio Benavent Oltra es Doctor en Filosofía y Letras (Pedagogía) y Master in Educational and Vocational Guidance. Profesor Titular de Universidad del Departamento de Didáctica y Organización Escolar de la Facultad de Filosofía y Ciencias de la Educación de la Universidad de Valencia. Líneas de investigación: Historia de la Orientación psicopedagógica en España; programas y metodología de la orientación y la toma de decisiones en la Educación Secundaria; análisis, evaluación y prospectiva de la Orientación psicopedagógica en la actual Reforma educativa. 
the state of the art in Guidance is suggested in order to discuss its possible functions within the coming society, in relation to: demographics (aging and migrations), youth, multiculture, technology, the school (specialization, diagnosis and reform), the labour world and its emerging trends and, finally, about the potential evolution of the current Guidance models. Suggestions are put forward, but the great questions still remain open. It concludes by emphasyzing that the objective of the paper was just to activate our creative thinking and motivate us to reflect upon our professional future.

Key words: Perspectives on Educational and Vocational Guidance. Prospective thoughts. Guidance models.

«Nuestra única certeza hoy es la incertidumbre. El futuro de la humanidad siempre ha sido incierto, pero las generaciones anteriores no eran conscientes de ello, bien porque vivían en una época cíclica en que todo recomenzaba perpetuamente, o porque su idea del tiempo estaba bajo el control remoto del imán o la flecha del progreso».

(Morin, 2002:68)

\section{Introducción}

«El dios Apolo, por medio de su oráculo en Delfos, profetizó a Layo que moriría a manos de su hijo y que posteriormente éste se casaría con la reina Yocasta, su madre. Para evitar tan terrible desgracia, el rey abandonó al niño en el monte Citerón, donde esperaba fuera devorado por las alimañas».

Así comienza, a grandes rasgos, la leyenda de Edipo, enriquecida sustancialmente tanto en calidad literaria como en matices de contenido en la obra Edipo rey (Sófocles): el rey queriendo evitar su destino, trata de matar a su propio hijo, propiciando sin saberlo, que su destino se cumpliera.

Esta leyenda inspira inquietantes interrogantes que suscitan nuestra reflexión filosófica referida al conocimiento del futuro, por ejemplo: Aunque conociéramos nuestro futuro, un horrible futuro, ¿no podríamos hacer nada para evitarlo? Es más, ¿todo lo que hiciéramos estaría encaminado fatalmente a su consecución (como se sugiere en la película «12 monos»)? ¿Significaría esto que el futuro ya está escrito? y, de no ser así, lo mas importante: ¿cómo podríamos cambiarlo?

Estas y otras preguntas surgen en nuestra mente cuando entramos en los territorios de la predicción e intentamos vislumbrar lo que traerán consigo los próximos años, porque a fin de cuentas, el adivinar el futuro es algo propio de augures, visionarios, o escritores de ciencia ficción, y sus especulaciones no se pueden basar más que en meras elucubraciones y suposiciones sin fundamento científico, es algo que entra en el terreno de la imaginación, la premonición, la intuición, la magia y los sueños... ¿o no? ¿O creemos en la ciencia prospectiva del Club de Roma y de los institutos norteamericanos especializados en diseñar horizontes futuros a plazo fijo? 


\section{La prospectiva. ¿EI nuevo oráculo?}

Desde el principio de los tiempos al hombre le ha interesado saber lo que le depararía el futuro. Ha sido una constante innata al ser humano. Magos, chamanes, oráculos y adivinos han desentrañado a lo largo de la historia los designios del fatum, el devenir, la fortuna, la buenaventura, en fin, el destino.

Pero actualmente, con esta manía tan propia de nuestros tiempos de convertir en técnico y científico todo lo que nos rodea, incluso lo más irracional y mágico, hemos convertido la investigación sobre el futuro en una ciencia a la que hemos bautizado con el nombre de Prospectiva. También ha cambiado el objetivo de esta predicción del porvenir, el futuro ya no nos interesa solo como satisfacción de nuestra curiosidad, o como un modo de preparación para lo que se nos viene encima, ahora nos interesa en tanto en cuanto nos sea aprovechable en el presente, es decir, no nos preocupa el futuro en si, sino como afecta este futuro al presente, al momento inmediato, y si desde el presente podemos manipular el futuro.

Según el Diccionario de la Real Academia de la Lengua Española, prospectiva es el «conjunto de análisis y estudios realizados con fin de explorar o predecir el futuro en una determinada materia» (RAE, 1992, II:1680). No obstante, la realidad es mucho más compleja. Esta técnica se divide en dos categorías diferentes. Por un lado, la prospectiva exploratoria, que intenta analizar los posibles caminos del futuro, y por otro, la prospectiva normativa, que en función de ciertos indicadores y valores identificados y reconocidos en las investigaciones sobre el tema, establece las actuaciones más convenientes. Es prácticamente imposible un análisis prospectivo exclusivamente normativo o exploratorio, y el mejor ejemplo lo encontramos en los informes del Club de Roma. Dichos trabajos comparten actitudes exploratorias y normativas, y estas últimas prevalecen cuando los autores de los estudios recomiendan avanzar hacia un mundo sostenible. De algún modo, en ese momento se realiza un cierto juicio de valor sobre la manera en la que el problema debería ser analizado. Esta mezcla entre análisis puro y duro y simples recomendaciones tiene una lógica aplastante. Tal y como afirma Jorge Pérez Martínez, director del Departamento de Prospectiva de FUNDESCO, «la nueva ciencia es interesante sólo en tanto en cuanto sea capaz de tomar decisiones en el presente». O lo que es lo mismo, no sirve de nada desentrañar las bifurcaciones del futuro, si luego somos incapaces de evitar lo que no deseamos.

H. G. Wells, el célebre escritor británico de ciencia ficción, ya advirtió en 1902 la importancia creciente de la previsión del futuro. Así, en una conferencia pronunciada el 24 de enero de dicho año en la Royal Institution de Londres expresaba su convicción de que las ciencias sociales tenían que orientarse hacia el porvenir (Wells, 1984). Pero la sociedad occidental tardó más de medio siglo en oír sus palabras. Tendrían que llegar personalidades de la talla de Bertrand de Jouvenel (1966) o Alvin Toffler (1980) para que la prospectiva se introdujera definitivamente en nuestras vidas.

Este retraso en la implantación de una ciencia tan interesante tiene una causa muy sencilla: los estudios de prospectiva requieren mucho tiempo y un considerable esfuerzo. Por ejemplo, el método Delphy, una de las técnicas más elementales utilizadas por los prospectivistas para el pronóstico de fechas, supone: 1) Hacer una concienzuda encuesta a un grupo de expertos en el tema que se pretende analizar, a la que contestan de forma individual, sin conocer la respuesta de los demás. 2) Posteriormente se tabulan las respuestas, se evalúan y 
se hace una media. 3) Los resultados son devueltos a los expertos para su análisis y reflexión y 4) Vuelven a emitir una opinión.

Para realizar este breve ensayo sobre el futuro de la Orientación en España me basaré en mis lecturas, mi experiencia y mis intuiciones. Mi propósito es humilde, no pretendo hacer un estudio prospectivo, no está a mi alcance, solo esbozaré algunas ideas que nos ayuden a reflexionar, o a soñar, sobre el posible devenir de la Orientación Psicopedagógica en nuestro contexto socio-cultural.

\section{El presente}

Ya que no existe posibilidad de proyectarse con éxito en el futuro, sin establecer una sólida plataforma en el presente enraizada profundamente en nuestro pasado, analizaremos brevemente el estado actual de la Orientación en nuestro país, que aunque a nivel institucional se desarrolló y divulgó a partir de la transición política del tardo-franquismo a la democracia, no es menos cierto, que sus orígenes se remontan a principios del s. XX con la creación de los Institutos de Orientación Profesional de Barcelona (1918) y Madrid (1924) y su posterior evolución hasta el momento presente (Benavent, 1996 y 2000).

A partir de 1977 aparecerán con carácter experimental los primeros Servicios Provinciales de Orientación Escolar y Vocacional (SOEV), retomando un modelo ya esbozado en el Estatuto de Formación Profesional de 1928. Este modelo de servicios va a tener vigencia hasta nuestros días. En 1978, con la nueva Constitución Española del Estado de las Autonomías, este paradigma va a evolucionar de forma paralela en el territorio MEC y en las primeras Comunidades Autónomas con competencia en materia educativa (Cataluña, País Vasco, Galicia, Valencia, Andalucía, Canarias y Navarra), actualmente las 17 del Estado Español, aunque en cada una de ellas se usará una terminología diferente para denominar unos servicios de apoyo psicopedagógico a la escuela básicamente idénticos.

En 1987 el Ministerio de Educación y Ciencia hizo público el documento Proyecto para la Reforma de la Enseñanza: Propuesta para el debate, (MEC, 1987), que contiene una serie de medidas favorecedoras de la práctica orientadora en los centros educativos, considerándola como una actividad que deben asumir los docentes y entendiéndola como un proceso continuo que implica la intervención de un conjunto de servicios internos y externos. Estas medidas se pusieron en marcha ese mismo año con la publicación de varias ordenes ministeriales, el Plan Experimental de Orientación y la convocatoria de 150 plazas de «Profesores orientadores» para los proyectos de Departamentos de Orientación en los centros de Enseñanza Media.

Será a partir del «Libro Blanco» (1989) y la posterior promulgación de la LOGSE (1990), cuando se realicen los primeros intentos para pasar de un modelo de servicios a un modelo de programas, aunque previamente, a principios de la década de los 80 , en medios universitarios se hablaba ya del modelo de programas, siguiendo las corrientes vanguardistas norteamericanas. El documento programático del MEC, La Orientación Educativa y la Intervención Psicopedagógica (1990), desarrolla el paradigma organizativo y funcional, esbozado en el «Libro Blanco» (1989), en los tres niveles en que actualmente se estructura el subsistema de Orientación en el seno del Sistema Educativo vigente: a nivel de aula, la $\mathrm{Tu}$ toría; a nivel de centro, el Departamento de Orientación y a nivel de sistema, los Equipos 
de Orientación Educativa y Profesional (EOEP). Este paradigma institucional, actualmente vigente, pretende dar respuesta a las necesidades individuales de los miembros de la comunidad educativa (alumnos, tutores y familias) combinando la intervención personalizada con el desarrollo de programas, modelo que fue denominado por Rodríguez Espinar (1993) como de «servicios actuando por programas».

Como colofón a las anteriores notas sobre la situación de la Orientación psicopedagógica en nuestro sistema educativo en estos últimos tiempos, solo me resta añadir las reflexiones que hace diez años me aventuré a lanzar sobre el futuro inmediato (hoy ya tiempo histórico) del mundo del trabajo, la inserción laboral de los escolares y la nueva finalidad de la Orientación Profesional:

«Los cambios que se avecinan en el sistema educativo y en el mundo del trabajo van a ser más rápidos que los producidos en el pasado, y a medida que la tecnología se va incorporando a todos los niveles de nuestro sistema social, el ritmo de estos cambios puede incrementarse todavía más. La nueva década se va a caracterizar por un auge del autoempleo y la proliferación de las pequeñas empresas, un aumento considerable de puestos de trabajo en el sector terciario, un constante reciclaje y adaptación («recurrent education») de los trabajadores y profesionales (que prácticamente se mantendrán en las mismas tareas actuales) en el uso de las nuevas tecnologías (informática y telemática) que invadirán nuestro medio laboral, y finalmente, en un predominio de las titulaciones cortas frente a las de larga duración. Los nuevos problemas personales de ajuste laboral asociados con esta nueva situación son un reto para la Orientación Profesional. Los orientadores tendremos que luchar contra la constante despersonalización del mundo del trabajo propiciada por el incesante impacto tecnológico, la fragmentación de las tareas y el aumento de los automatismos y rutinas ocupacionales, a fin de encontrar nuevos medios y procedimientos para ayudar, a todo aquel que solicite consejo, a integrar el trabajo como parte importante de su sistema personal de valores» (Benavent, 1992: 56-57).

\section{El futuro: La orientación inmersa en una encrucijada sociocultural}

\section{Demografía: envejecimiento e inmigración}

Al despuntar el s. XXI todos los medios de información se hicieron eco de la noticia de que ya éramos 6.000 millones de seres humanos sobre la faz de la Tierra. A estas horas el número habrá aumentado ya significativamente, pues a pesar de que hemos tardado unos cuantos cientos de miles de años en llegar a esta multimillonaria cifra, el doblarla podría llevarnos menos de cinco décadas. La población de la Tierra crece de forma alarmante, mientras que la de la Unión Europea en general, y la de España en particular, decrecen vegetativamente. Este desequilibrio no puede mantenerse, y de hecho la balanza empieza a dar síntomas de equilibrarse gracias a la incesante inmigración que ha cambiado el signo de la tendencia decreciente. Mucho se está hablando de si esta corriente migratoria es beneficiosa o perjudicial, si los inmigrantes quitan puestos de trabajo, incrementan la delincuencia y aumentan las cargas sociales, o por el contrario, esta nueva fuerza laboral será imprescindible para el sostén de nuestras pensiones en la vejez y el rejuvenecimiento de nuestras poblaciones. Sea como fuere, no podemos frenar lo inminente: ahí están las alambradas de impermeabilización fronteriza de Ceuta y Melilla, las pateras encallando en las costas de Fuer- 
teventura y cruzando el estrecho de Gibraltar diariamente, la nueva Ley de Extranjería, y los magrebíes, subsaharianos, rumanos, bosnios, rusos, servios, ecuatorianos, colombianos, etc. que se infiltran silenciosamente en nuestro tejido social. España está llamada a ser en un futuro próximo lo que siempre fue, un crisol de culturas, y esto se reflejará en todos los aspectos de la vida: las leyes, la educación, la economía, la religión, las estructuras sociales, etc. En definitiva, la inmigración conformará en los próximos años un nuevo tejido social y cultural complejo, rico, conflictivo y difícil de gestionar (Pimentel, Jiménez y Echeverría, 2002).

También cambiarán las infraestructuras y las ciudades se transformarán en megalópolis. Las distancias entre ellas se acortarán con medios de transporte más rápidos y las relaciones humanas evolucionarán en estos gigantes urbanos: o hacia un comunitarismo donde la intimidad no tendrá cabida, o bien hacia una territorialidad llevada al extremo, donde todas las personas serán muy independientes y renuentes al contacto social. Este cambio en las relaciones ya se está apuntando con el excesivo aislamiento de los niños, en su mayor parte hijos únicos, que se encierran en sus casas con la única compañía de game-boys, playstations, robotic-pets, videos, DVDs, ordenadores, Internet, etc. todo lo cual influirá de forma notable en la evolución de la Orientación Psicopedagógica y sus nuevas funciones relacionadas con la prevención y el tratamiento de los problemas suscitados por la falta de socialización de las nuevas generaciones y la aparición de nuevas patologías generadas por la soledad, la «teleadicción», la «burbuja cultural», las «ciberdependencias», etc.

Por otra parte, nos enfrentamos con el hecho incuestionable del incesante envejecimiento de nuestra población. Nacen menos niños y la esperanza de vida de los españoles se ha duplicado en el s. XX, pasando de 40 años en 1900 a 80 en el 2000. Además, la edad de permanencia activa en el mundo laboral se reduce al aumentar los periodos de educación obligatoria y disminuir la edad de jubilación. Debido a una notable mejora en la alimentación, los españoles de las nuevas generaciones maduran antes, son más altos, más robustos y activos sexualmente, en general, más precoces que sus abuelos, pero no se emancipan hasta los treinta años, y es que hoy por hoy, tenemos los jóvenes más viejos de la historia. Esta situación, si no se soluciona con la inmigración u otras medidas demográficas, nos llevará a un desequilibrio económico (población activa, generadora de recursos Vs. población pasiva, consumidora de recursos: pensiones / educación / sanidad / ocio ...,), que hará insostenible el actual «estado del bienestar», y con él, el Estado como suministrador de prestaciones sociales, lo que conllevará el fin de un sistema educativo de calidad, y por consiguiente del subsistema de Orientación psicopedagógica implícito.

\section{Juventud}

Los jóvenes de hoy son un manifiesto de lo que nos depara el mañana. En un reciente estudio la mayoría de los jóvenes declara que lo más importante para ellos es la familia (Urías, 2000). Esta ya no es autoritaria como en el pasado, es más democrática, se da mayor libertad a los hijos y se les sigue manteniendo, por eso no es de extrañar que la emancipación no se halle entre sus prioridades. Este gusto por el ambiente familiar no tiene porqué cambiar, aunque cambie la familia (hijos a edades más maduras, nueva distribución de los roles, disciplina más flexible, parejas de hecho, parejas homosexuales...), que seguirá siendo un ámbito de intervención psicopedagógica de gran importancia. 
En la actualidad predomina la tendencia de traspasar parte de los papeles que tenía la familia tradicional para con los hijos (valores, autoridad, disciplina, ...), a manos de otras instituciones como la escuela, como argumenta el informe de la Comisión Internacional sobre la Educación para el s. XXI de la UNESCO presidida por Delors: «...se exige mucho al docente, incluso demasiado, cuando se espera que calme las carencias de otras instituciones también responsables de la enseñanza y la formación de los jóvenes. Mucho se le pide, mientras que el mundo exterior entra cada vez más en la escuela, en particular a través de los nuevos medios de información y comunicación. Así pues, el maestro se encuentra ante jóvenes menos apoyados por las familias o los movimientos religiosos pero más informados. Por consiguiente, debe tener en cuenta ese nuevo contexto para hacerse escuchar y comprender por los jóvenes, para despertar en ellos el deseo de aprender y para hacerles ver que la información no es conocimiento, que éste exige esfuerzo, atención, rigor y voluntad» (Delors, 1996: 30). Todo ello va a conllevar que la intervención psicopedagógica se preste prioritariamente en otros ámbitos, sobre todo si es una intervención preventiva, en la que es necesaria una mayor organización, previsión y dedicación.

La despreocupación por el futuro, el llamado presentismo, es una de las características de la juventud actual que más influirá en el porvenir. Existe una desconfianza ante todo, propia de los jóvenes de cualquier época, pero unida a un sentimiento de no poder hacer nada por solucionarlo, que les lleva a centrarse en el hoy: estudian, trabajan, se preparan por una vaga conciencia de lo que deben hacer o por consejo de los padres, no con vistas a un futuro. Si esta tendencia se mantiene, si la juventud abandona el afán de lucha para labrarse un porvenir, si la ilusión por la promoción personal y la emancipación familiar decrece, la Orientación perderá su razón de ser, puesto que se orienta para encaminar al sujeto hacia su futuro, y si este no interesa ¿para qué orientar?

\section{Multiculturalidad}

Actualmente ya existen colegios en numerosas ciudades españolas que escolarizan a un gran número de hijos de inmigrantes, y este fenómeno se irá incrementando en el futuro. Es evidente que al hablar de inmigración hemos de hablar también de multiculturalidad. Los curriculos tendrán que flexibilizarse y no solo se producirán cambios en los contenidos de las materias, también en la forma de tratarlas y los métodos y estrategias didácticas tendrán que adecuarse para dar respuesta a las necesidades educativas de los niños de familias con culturas muy diferentes. Esta adaptación, esta multiculturalidad, no se limitará al mundo académico, afectará a todos los campos de la vida cotidiana: el trabajo (estableciéndose pausas para los rezos, adaptaciones del horario para el ramadán, formas de trabajo alternativas...), el comercio (nuevos artículos que cumplan ciertas características, por ejemplo, alimentos kasher, o sea, comestibles para los judíos ...), el arte, las ciencias, la publicidad, etc. En el campo de la Orientación psicopedagógica esta variedad de culturas tendrá que considerarse tanto en la elaboración de los diagnósticos (confección del historial personal de los individuos y otras informaciones previas que nos ayuden a ilustrar el diagnóstico y a descubrir las posible causas de los problemas), como en las intervenciones (en que ámbitos de su vida podremos actuar y de que forma), por lo que cobrará especial relevancia el multicultural counseling. 
La xenofobia será un mal que seguramente tendremos que tratar en la nueva sociedad multicultural que se avecina, los primeros síntomas ya se han hecho notar. Según estudios realizados recientemente, los jóvenes se consideran solidarios y tolerantes, pero son muy pocos los que trabajan en ONGs o aceptan sin renuencias a etnias como la gitana. Por tanto, la tolerancia y la convivencia serán dos valores que deberemos propiciar (y de hecho ya empezamos a hacerlo) en los programas transversales integrados en los currículos escolares, en los específicos de «atención a la diversidad» y en los PAT.

\section{Tecnología}

La sociedad que viene será una sociedad cada vez más tecnificada, tendente a lo que ya se conoce como «sociedad red» (Castells, 1998-99). Dentro de muy poco todo lo que nos rodea estará dotado de un chip, el siguiente peldaño será la creación de redes que establezcan y mantengan el contacto entre los millones de chips que constituirán el nuevo medio informático que envolverá nuestra existencia, por fin, con Internet III entraremos en una conexión total, inauguraremos la «aldea global del conocimiento» y se cumplirá la profecía de Teilhard de Chardin (1967) con el inicio sobre la faz de la Tierra de la era de la «noosfera».

La «red de redes» será algo tan consustancial y tan cotidiano en nuestra vida que no le daremos ninguna importancia, pero que nos permitirá tener acceso a tal cantidad de datos y realizar tantas actividades desde nuestra propia casa, que quizás ya no necesitemos salir de ella, con el consiguiente menoscabo de nuestras relaciones sociales presenciales y el surgimiento de un nuevo mundo de «relaciones virtuales». Conseguiremos una existencia más plácida, en un mundo globalizado en torno a la facultad de interactuar y responder al goteo incesante de estímulos electrónicos con que nos bombardeará la recién alumbrada y superexigente «tecnosociedad de la cibercultura» (Aronowitz et al., 1998).

La siguiente cuestión que se plantea es: ¿Sabremos utilizar éticamente estas nuevas tecnologías?, en otras palabras, ¿las nuevas tecnologías permitirán la integración de todos los seres humanos o se alienará a la mayoría en beneficio de una casta dominante que solo fabricará y comercializará aquello que garantice la supremacía de una élite «ciberalfabetiza$d a »$ frente a unas masas de «ciberanalfabetos», tecnofóbicos y apocalípticos desheredados de la gran fortuna, convertidos en ceros y unos tan desprovistos de sentido como los impulsos electrónicos circulantes por Internet? Volviendo la vista atrás parece más propio de la condición humana la segunda opción, por tanto uno de los retos para las próximas décadas será el autocontrol ético de la infinita capacidad autosuperadora de los propios soportes tecnológicos con que nos vincularemos y relacionaremos en un mundo donde todo será un apéndice de un «algo» más grande, potente y universal.

Además de este aprovechamiento más o menos ético de los recursos cibernéticos, el avance propiciado por la tecnociencia traerá consigo otras consecuencias importantes: por ejemplo, supongamos que dentro de unos cincuenta años la robótica ha conseguido que la mayoría de los trabajos psicofísicos los realicen las máquinas, esto supondrá que una gran masa de trabajadores tendrá que ser reciclada para desempeñar nuevas actividades laborales o lúdicas y en estas tareas la Orientación psicopedagógica jugará un papel determinante.

La Orientación también se beneficiará de las nuevas tecnologías incorporando todos aquellos avances que permitan mejorar: a) La información y el registro de datos de las per- 
sonas que solicitan ayuda; b) La medida psicotécnica de sus aptitudes y rasgos de la personalidad; c) La confección de diagnósticos más precisos; d) La elaboración de todo tipo de programas individualizados; e) La información actualizada de los itinerarios académicos y profesionales; f) La situación de la bolsa de trabajo, etc. Todas estas actividades podrán realizarse sin que el sujeto tenga que moverse de su casa, e incluso las entrevistas podrán mantenerse interactivamente a través de la «red de redes». Sin embargo no todo serán ventajas y surgirán nuevos problemas y dificultades relacionados con nuestra condición humana (emociones, afectos y sentimientos) difíciles de solucionar por medio de la tecnología.

\section{Escuela: especialización, prevención y reforma}

A parte de la posibilidad de que la escuela desaparezca en un futuro más o menos lejano, como lugar o espacio físico temporal y templo del aprender, en favor de una instrucción permanente y autónoma desde la propia consola del ordenador vía Internet, actualmente ya detectamos en la LOGSE (1990) y sus disposiciones complementarias una tendencia hacia una mayor especialización académica, tendencia que se ve reforzada con la implantación de los nuevos Bachilleratos LOGSE y la modulación de las nuevas titulaciones universitarias en curso. Ante esta situación cabe preguntarse: ¿Llegará un momento en el que nada más nacer ya se averigüen las aptitudes del bebé y se le preparará desde la cuna para su puesto en el mundo, o incluso llegaremos más lejos y se «creará» (en el sentido más estricto de la palabra), como en el libro de Aldous Huxley (1969), Un mundo feliz, el mejor hombre para el mejor trabajo? En tal caso, ¿qué sentido tendría la Orientación psicopedagógica?

Por otra parte, los espectaculares avances de la genética y la detección cada vez más temprana de todo tipo de dolencias y deficiencias humanas, como las enfermedades y deterioros mentales, la diabetes y sus secuelas, las parálisis degenerativas o el cáncer (incluso antes de que se manifiesten), propiciarán una profilaxis o una educación para la prevención, pudiendo llegar los nuevos expertos a minimizar los efectos no deseados o incluso a evitarlos. De ahí que, en un futuro próximo, se haga necesario desarrollar una Orientación para la salud y la higiene mental potenciando su dimensión preventiva, con bases más científicas y la participación decidida del médico en el equipo orientador con una tecnología punta que facilitará el diagnóstico precoz, tal como lo hemos podido ver realizado en la película de ciencia ficción «Gattaca».

La integración de niños con NEE en el aula ordinaria continuará, y afortunadamente estamos apostando por la atención a la diversidad y la «escuela inclusiva» (Stainback y Stainback, 1999; Ainscow, 2001; Revista de Educación, 2002). Pero en el futuro cada vez habrá menos niños que integrar, puesto que con los avances de la genética y la prevención, ya no nacerán niños con deficiencias y si lo hacen, estas podrán ser corregidas. Esperemos por nuestro bien que esta homogeneización no se lleve hasta el extremo de «corregir» las diferencias individuales (aunque la discusión sobre la clonación de seres humanos en los foros científicos me hace pensar lo peor), puesto que son precisamente estas diferencias las que nos han permitido progresar como especie, evolucionar y llegar a lo que hoy somos, mientras que la homogeneización, al no permitir las divergencias, puede suponer la paralización del proceso de humanización, y como todos sabemos, una sociedad que no avanza, se estanca y desaparece. 
Junto con estas previsiones globales a largo plazo y ciñéndonos al contexto de nuestro sistema educativo, hay que señalar, que aunque la reforma de la LOGSE supuso en los años de 1990 un auténtico cambio cualitativo (organizativo, funcional, estructural y curricular), este proyecto tuvo que enfrentarse a lo largo de su implantación y desarrollo, con escasa financiación y dudoso apoyo político para tratar de resolver las graves disfunciones endémicas que se arrastraban desde la LGE (1970) y las nuevas dificultades aparecidas en la última década del s. XX. Una reforma que mejoró indudablemente la educación, pero que se está mostrando incapaz de resolver los últimos desajustes y retos educativos que la sociedad actual le está planteando, con lo que se hace necesario, en un futuro inmediato, introducir e impulsar como mínimo las siguientes iniciativas para tratar de resolver los principales problemas detectados (Marchesi, 2001, 2002): a) Mayor autonomía a los centros para que desarrollen proyectos propios y los acuerden con la administración educativa. b) Impulsar el desarrollo profesional de los profesores. c) Apoyo a los centros situados en contextos desfavorecidos y a los alumnos con mayores dificultades de aprendizaje, y d) Ampliar las formas de participación y cooperación entre escuelas y profesores que propicien nuevas oportunidades para la innovación y el cambio. Estas posibles y deseables mejoras «son propuestas que apuestan por una educación de calidad para todos los alumnos y que tienen como objetivo que las escuelas se constituyan en comunidades de aprendizaje. Por ello, se apartan de aquellos otros modelos educativos que basan la mejora de la calidad en la competencia entre los centros, en la vuelta a los modelos tradicionales de enseñanza, en la rigidez organizativa y en la selección del alumnado» (Marchesi, 2001: 72).

Frente a estas propuestas, el Gobierno del PP presenta el nuevo Proyecto de Ley Orgánica de Calidad de la Educación aprobado por el Consejo de Ministros (26/07/02) y que pasará al Parlamento en la próxima Legislatura (2002-03) para su debate por parte de los grupos políticos. La nueva Ley de Calidad de la Educación (LOCE) pretende corregir y actualizar la LOGSE (1990) y «acometer una reforma educativa que permita subsanar los fallos y deficiencias del actual modelo; de mejorar la calidad del sistema educativo; de reducir el índice de fracaso escolar; y de fomentar la cultura del esfuerzo y de la evaluación». El texto completo del Proyecto se encuentra disponible en la página web del MECD en Interrnet en la siguiente URL: http://www.mec.es/

El futuro inmediato del sistema educativo y de la escuela en nuestro país, en espera de la aprobación y posterior implantación del presente Proyecto como Ley Orgánica, se desarrollará de acuerdo con los objetivos formulados y la puesta en práctica de las siguientes medidas implícitas en el mismo:

- El proyecto de Ley tiene como principal objetivo impulsar un sistema efectivo de calidad y oportunidades para todos. Para ello, introduce medidas que mejoran la cualificación y la formación de los alumnos, al tiempo que garantizan el máximo grado de integración.

- Se reconoce a todos los alumnos los mismos derechos y deberes, sin más distinciones que las derivadas de la edad y del nivel que estén cursando.

- Se reconoce a todos los alumnos, entre otros derechos, a que su dedicación y esfuerzo sean reconocidos y evaluados con objetividad, y a recibir orientación educativa y profesional. 
- Se pretende reducir el índice de fracaso escolar, elevar el nivel de formación de los alumnos, fomentar la cultura del esfuerzo y mejorar las condiciones para el desarrollo de la función docente.

- Se suprime la promoción automática. Los alumnos con tres o más asignaturas suspendidas repetirán curso. Se establecen pruebas extraordinarias de recuperación en Secundaria.

- En $3^{\circ}$ y $4^{\circ}$ de la Educación Secundaria Obligatoria, y con el fin de atender la pluralidad de necesidades e intereses de los alumnos, se organizarán distintos itinerarios formativos.

- Los itinerarios, que serán de libre elección por parte de las familias, con la orientación del centro, constarán de materias comunes y específicas. Todos ellos conducirán al mismo título. Se prevé la movilidad entre los itinerarios.

- Se establece una Prueba General de Bachillerato (PGB), tal como ocurre en la mayoría de los países de la UE, para homologar los conocimientos. La nota del título de Bachiller será la media del expediente y la calificación de la PGB.

- Se establecen Programas de Iniciación Profesional, con una duración de dos años, que sustituyen a la actual Garantía Social, y que significan una nueva opción conducente a título para aquellos estudiantes que no consigan los objetivos de la Educación Secundaria Obligatoria.

- Se desarrolla la evaluación del sistema educativo a través de pruebas de diagnóstico.

- Se pretende reconocer y estimular el trabajo de los docentes. Se refuerza la importancia de la formación de los profesores, tanto inicial como permanente. Además, se establecen medidas de apoyo a la función docente.

- Se estructura una carrera docente sólida con mayores posibilidades de promoción, que tiene como último tramo el restablecido Cuerpo de Catedráticos.

- Se refuerzan las competencias de la función directiva, y se modifica el sistema de elección de los directores, otorgando más protagonismo a los profesores.

- Se introducen medidas encaminadas a mantener la convivencia y la disciplina en las aulas.

- Se dota de mayor autonomía a los centros escolares.

- La Educación Infantil (3-6 años) será gratuita para atender las demandas de las familias. En esta etapa, se introduce el inicio del aprendizaje de lectura, escritura y habilidades numéricas; y además, se podrá iniciar el estudio de una lengua extranjera y de las nuevas tecnologías.

- En Primaria, se revisarán las enseñanzas mínimas para potenciar las áreas instrumentales (Lengua y Matemáticas), las Lenguas Extranjeras y el fomento de la lectura.

Esperemos que esta vez no se comentan los errores seculares de nuestra historia reformista del sistema educativo, y se cuente por vez primera, con la adecuada financiación y el necesario apoyo político, institucional y social para que la actual Reforma en proyecto sea la que nuestra sociedad precisa y se puedan alcanzar en los próximos años los objetivos anteriormente enunciados. 


\section{Trabajo: tendencias emergentes}

En los años finales del s. XX, el amplio y complejo mundo laboral de la UE se encontraba inmerso en la era post-industrial o postmoderna, en la que los tradicionales conceptos de trabajo y carrera hicieron crisis y empezaron a sufrir dramáticos cambios con significativas consecuencias para la educación y formación profesional, el mercado del trabajo y la Orientación Profesional, cambios a los que dedicamos especial atención en anteriores trabajos (Benavent, 1992, 1999).

Para intentar trazar las coordenadas que caracterizarán el mundo del trabajo en un futuro a corto plazo es necesario partir de un análisis de la situación actual, ya que ésta constituye el germen de la sociedad emergente que está siendo modelada, tanto por acontecimientos azarosos e imprevisibles, como el ataque terrorista y la destrucción de las Torres Gemelas de Nueva York el 11 de septiembre de 2001, como por las previsiones basadas en las más rigurosas reflexiones de la realidad política, social y económica que estamos viviendo: «La revolución de las tecnologías de la información y la reestructuración del capitalismo han inducido una nueva forma de sociedad, la sociedad en red, que se caracteriza por la globalización de las actividades económicas decisivas desde el punto de vista estratégico, por su forma de organización en redes, por la flexibilidad e inestabilidad del trabajo y su individualización, por una cultura de la virtualidad real construida mediante un sistema de medios de comunicación omnipresentes, interconectados y diversificados, y por la transformación de los cimientos materiales de la vida, el espacio y el tiempo, mediante la constitución de un espacio de flujos y del tiempo atemporal, como expresiones de las actividades dominantes y de las élites gobernantes» (Castells, 1998: 23).

La diversidad de estructuras ocupacionales que caracterizaban el mundo del trabajo se han visto seriamente afectadas por estos hechos, que han propiciado su adaptación y reorganización de acuerdo con los actuales parámetros estratégicos, políticos, sociales y económicos emergentes, los cuales están generando nuevos y significativos cambios en: a) Las características demográficas de la población laboral (envejecimiento, edad de jubilación y de acceso al primer trabajo, incorporación de la mujer, movimientos migratorios, etc.). b) Los excedentes de mano de obra y los índices de paro. Se observan crecientes incrementos de dichos indicadores como consecuencia de la incesante implantación de las nuevas tecnologías de la información y la comunicación y de las nuevas estrategias geo-políticas de los mercados. c) La organización laboral y las ocupaciones. Se ven afectadas por: la globalización del mercado del trabajo; la nueva legislación laboral generada por las presiones éticas, políticas, económicas, ecológicas, etc.; el trabajo temporal y a tiempo parcial; el trabajo creativo y autónomo («los emprendedores»); la formación y reciclaje constante de los trabajadores; el puesto de trabajo flexible, descentralizado, a distancia, atemporal y virtual; la mejora de la calidad de vida y de las condiciones laborales, etc., y d) Las cualificaciones de los trabajadores. Mientras muchos profesionales y operarios no encuentran trabajo por que su especialización está obsoleta, o no se precisa en los nuevos procesos productivos, los campos ocupacionales emergentes de las tecnologías punta no encuentran personal capacitado para desarrollar tareas analíticas, simbólicas y heurísticas, donde la inteligencia adaptativa y la creatividad son cada vez mas apreciadas (Tractenberg, Streumer and Van Zolingen, 2002).

Ante esta situación, los políticos y empresarios están tomando decisiones que van a afectar profundamente la formación profesional de las nuevas generaciones de trabajadores 
durante los próximos años, a fin de adaptarla a las demandas del mercado del trabajo y de las nuevas cualificaciones que éste requiere. En España se acaba de aprobar la nueva Ley de las Cualificaciones y la Formación Profesional (Ley Orgánica 5/2002) que «tiene por objeto la ordenación de un sistema integral de formación profesional, cualificaciones y acreditación, que responda con eficacia y transparencia a las demandas sociales y económicas a través de las diversas modalidades formativas» (Art. 1.1). La regulación de estas enseñanzas que la nueva Ley pretende llevar a cabo en los próximos años parte, «...como noción básica, del concepto técnico de cualificación profesional, entendida como el conjunto de competencias con significación para el empleo, adquiridas a través de un proceso formativo formal e incluso no formal que son objeto de los correspondientes procedimientos de evaluación y acreditación. En función de las necesidades del mercado de trabajo y de las cualificaciones que este requiere, se desarrollarán las ofertas públicas de formación profesional, en cuya planificación ha de prestarse especial atención a la enseñanza de las tecnologías de la información y la comunicación, idiomas de la Unión Europea y prevención de riesgos laborales» (Exposición de motivos).

Así pues, en el nuevo mundo del trabajo que está amaneciendo y que se desarrollará en los próximos años se precisará que los trabajadores estén capacitados para tomar decisiones, solucionar problemas y operar independientemente, trabajar en escenarios cada vez mas indefinidos, ser mas creativos, poseer un amplio conocimiento de los sistemas productivos en los que están inmersos y de su tecnología punta, tener un conocimiento más completo de las tareas que están desempeñando, obtener, organizar e interpretar información de las redes telemáticas, establecer y mantener contactos virtuales y desarrollar nuevas habilidades sociales, tales como negociación y solución de problemas o estrategias para la mejora de las interacciones con los miembros del grupo de trabajo a nivel personal y virtual (Nijhof, 1998). En este nuevo escenario laboral, las empresas, además de satisfacer un salario económico justo, tendrán que considerar el salario emocional, que requerirá un continuo ejercicio de comprensión para dar al empleado «una satisfacción personalizada» (Pimentel, Jiménez y Echeverría, 2002).

Todos estos cambios están incidiendo en la tradicional concepción del trabajo y del sistema de empleo, propiciando una profunda reconceptualización del significado y el desarrollo de la «carrera individual». En los próximos años el pleno empleo será una utopía del pasado, un trabajo para toda la vida será un privilegio para unos pocos, el cambio de ocupación y la movilidad laboral irán en constante incremento, la alternancia entre los períodos de formación, desempleo, subempleo y de trabajo productivo será un proceso continuo y el concepto de «desarrollo de la carrera» dejará de ser sinónimo de desarrollo del trabajo o empleo. En definitiva, en nuestra sociedad red o sociedad de la información, está emergiendo un nuevo modelo dinámico de mercado de trabajo que se estructurará en tres niveles y que obligará a los trabajadores a una incesante adaptación al cambio a lo largo de su vida activa. El primer nivel se constituirá con los empleos manuales sin necesidad de cualificación, donde se integrarán la mayoría de los inmigrantes. Un segundo nivel estará formado por los servicios, donde la atención a los mayores y el turismo generarán las principales vías de empleo. El tercer nivel estará reservado a los directivos, técnicos y especialistas de las nuevas tecnologías de la información y la comunicación (Pimentel, Jiménez y Echeverría, 2002). 


\section{La respuesta: los modelos de la orientación}

«No esperes nada del siglo XXI, es el siglo XXI quien lo espera todo de ti».

(García Márquez)

En anteriores trabajos hemos definido la Orientación psicopedagógica como un campo científico multidisciplinar, aplicado y prospectivo, cuyo objetivo es prestar ayuda innovadora y eficaz para la autorrealización humana (Benavent, 1992 y 1999). Nosotros estamos llamados a ser uno de los agentes gestores de este proyecto, pues estamos empeñados en convertirnos en los Orientadores psicopedagógicos profesionalizados que espera la sociedad del siglo XXI. No podremos predecir el futuro, pero podremos laborar para modelarlo. Realizar el proyecto de humanización, no dependerá solo de nosotros, será una tarea colectiva, un ímprobo trabajo de equipo para responder a lo imprevisible, pero en gran medida estará en manos de cada uno de nosotros e irá tomando forma con la suma de los actos de la especie humana.

Para responder de manera oportuna a los retos del siglo XXI, debemos empezar planteando las preguntas adecuadas de modo que podamos identificar las soluciones posibles, si es que las hay, antes de que sea demasiado tarde. Éste es precisamente el papel de los estudios orientados hacia el futuro y el pensamiento avanzado, ésta es el área de las ciencias prospectivas entre las que tiene su lugar propio la Orientación psicopedagógica. ¿Cuál es nuestro papel como profesionales de este campo multidisciplinar, prospectivo y aplicado?: Intentar ir un poco por delante del juego, como el jugador de ajedrez que debe analizar la evolución potencial de cada fase del juego, mientras anticipa, tanto como sea posible, los movimientos de las diferentes piezas. Así podremos «... hacer camino al andar» junto con quien, o quienes, soliciten nuestra compañía para continuar progresando en la aventura de nuestra autorrealización humana.

Las viejas y siempre nuevas interrogantes del - ¿Quién soy?, ¿Dónde estoy? y ¿A dónde voy?-, ya formuladas por los pensadores de la Grecia clásica (s. V a. JC), así como las preguntas tradicionales que Kant formula en su obra Crítica del juicio (1790)-¿Qué puedo conocer?, ¿Qué podría hacer? y ¿Qué puedo esperar?-, se deberían reformular, por consiguiente, desde un punto de vista orientado hacia el futuro, donde el YO se reemplace por el NOSOTROS. De este modo, ya no debemos preguntarnos ¿Quién soy?, sino ¿Quiénes somos?; ni ¿Dónde estoy?, sino ¿Dónde estamos?; ni ¿A dónde voy?, sino ¿A dónde vamos?. Ni tampoco ¿Qué puedo conocer?, sino ¿Qué podemos conocer?; ni ¿Qué podría hacer?, sino ¿Qué podríamos hacer?; ni ¿Qué puedo esperar?, sino ¿Qué podemos esperar? Así pues, no nos preguntemos ¿Qué es el hombre?, sino ¿Qué somos y que queremos ser?, ¿Dónde estamos y donde queremos estar? y ¿A dónde vamos y a donde queremos llegar? Estas nuevas formulaciones de las inquietantes cuestiones de siempre, no son solo una simple solicitud de predicción, orientación o ayuda para la toma de decisiones y la realización de los proyectos de vida individuales, sino que nos implican en una empresa común, la de nuestra humanización. Introducir el NOSOTROS, supone construir de forma cooperativa nuestro futuro, asumir que solo nos humanizamos cuando compartimos generosamente nuestro presente con los demás para iluminar nuestro futuro, oscuro de incertidumbre y misterio, que de momento es nada, porque el futuro, por definición, no existe, pero siempre está a punto de existir y emerge a su debido tiempo (Bindé, 2002). 
Las reflexiones que acabamos de exponer y la lectura de la última Declaración sobre la Orientación Educativa y Profesional de la AIOEP, aprobada por su Junta Directiva en París, el 17 de septiembre de 2001, con motivo de la conmemoración del 50 Aniversario de su creación (IAEVG, 2002), así como las acertadas consideraciones críticas al qué, cómo y por qué a dicha Declaración realizadas por Van Esbroeck (2002), nos hacen pensar que en los próximos años los actuales modelos de Orientación sufrirán multitud de cambios para adaptarse a la sociedad que viene y a las necesidades de las personas del futuro. Por tanto, los modelos teóricos, de intervención y los organizativos deberán evolucionar y cambiar para acoplarse a la nueva sociedad o desaparecerán.

Los modelos teóricos a corto plazo no variarán sensiblemente, pues los principios (filosóficos, sociológicos y económicos), sobre los que se basan, son un sólido fundamento para la práctica orientadora, pero a largo plazo, con el surgimiento de nuevos planteamientos filosóficos se crearán nuevos modelos eclécticos de síntesis, sobre todo por los nuevos estilos de vida que surgirán en la «sociedad red».

Por lo que se refiere a los modelos de intervención, es lógico pensar que se propiciarán modelos mixtos con un alto componente tecnológico. Los cuatro modelos básicos actuales (clínico, servicios, programas y consulta), tenderán a desaparecer para, a largo plazo, ser sustituidos por modelos tecnológicos que a través de las redes informáticas y los bancos de datos (ya se está experimentando con los sistemas expertos microcomputerizados en el diagnóstico y tratamiento de las dificultades del aprendizaje), darán respuestas satisfactorias a las emergentes necesidades individuales y sociales y serán capaces de desarrollar realidades virtuales. Esto nos planteará un nuevo dilema: ¿El orientador será un ordenador? Desde un modelo de competencias este planteamiento no suscitaría demasiados problema, pero desde un modelo humanista centrado en la persona ¿Dónde quedaría el componente humano? ¿Cómo podría percibir un ordenador aquellas cogniciones, emociones y sentimientos que el sujeto no nos dice pero deja translucir? ¿Cómo se sentirá afectivamente el cliente interaccionando con una máquina?

A corto plazo, y para mejorar la eficacia de los modelos psicopedagógicos, surgirán modelos organizativos más sofisticados y con mayor componente informático, tanto en los sistemas escolares públicos y privados como en el mercado de trabajo. Modelos que facilitarán la intervención de los orientadores escolares y profesionales sobre los usuarios del subsistema de Orientación, asesoramiento y tutoría vigente, aunque las funciones básicas del orientador psicopedagógico en la actualidad y durante los próximos años son y seguirán siendo: (Jiménez, 1997; Benavent, 1999; Sanz, 2001): a) La de formador de formadores, asesorando e informando a profesores, padres, tutores y otros para-profesionales de las actividades formativas y educativas. b) Especialista en recursos comunitarios, a fin de facilitar el enlace entre las necesidades individuales y los medios formativos y laborales disponibles. c) Experto en el uso de las nuevas tecnologías de la información y la comunicación, herramientas imprescindibles para la mejora de los procesos y los productos de la orientación. d) Consultor, mediador y agente promotor de la innovación y el cambio adaptado a las características multiculturales de cada escuela y de su contexto socio-comunitario, y e) Unido a su función como consultor, intercesor y líder del cambio, el orientador psicopedagógico, dentro de la corriente científica de la Investigación-Acción, aparece como investigador en busca de soluciones prácticas a los problemas que suscita la vida académica y sus respectivos contextos socio-comunitarios (investigación orientada a resultados). A este respecto, hay que señalar por su relevancia a nivel internacional, el proyecto de investigación 
«Estándares de cualificación para orientadores», que bajo los auspicios de la IAEVG (Repetto et al., 2002) está indagando en estos momentos la importancia que se atribuye a las distintas competencias que los expertos de todo el mundo han identificado como relevantes para la cualificación de los orientadores, a fin de tenerlas en cuenta en la elaboración de futuros programas para su formación y perfeccionamiento profesional.

Una lectura rápida del Proyecto de Ley Orgánica de Calidad de la Educación (MECD, 2002), nos confirma que en su texto subyacen implícitas las funciones de formación, prevención, desarrollo, consulta, intervención e investigación, y que éstas, deberán ser desempeñadas por profesionales cualificados, en nuestro caso, por los Orientadores psicopedagógicos, pues «ya son varias las promociones de psicopedagogos que han culminado un proceso de formación de nivel superior, que los capacita no sólo para asumir cuantas funciones parecen atribuírseles en el sistema escolar, sino que también son capaces de depararnos un avance significativo del mismo, haciendo que esa calificación de "calidad" que se hace en la Ley, y que parece un eufemismo, se convierta en realidad, no por sus matices evaluadores ni dependiendo de calificaciones criteriales, sino desde la implementación efectiva de recursos que aporten excelencia al propio proceso educativo» (Quintanal, 2002:11).

Para finalizar estas breves reflexiones solo nos resta presentar un mapa conceptual (Fig. 1) que nos permita sintetizar y visualizar las principales ideas expuestas en relación con la educación y el mundo del trabajo.

\section{Conclusión}

Todas las civilizaciones que llegaron a un alto grado de desarrollo (egipcia, griega, romana, maya,...), al alcanzar su punto álgido de bienestar, su apogeo político y cultural, y comenzar a cosechar y disfrutar sus logros, iniciaron su decadencia. ¿Le volverá a ocurrir lo mismo a nuestra actual sociedad? ¿Hemos llegado ya a nuestro cenit socio-cultural?

Hemos reducido sensiblemente la morbilidad, aumentado el nivel de vida de modo espectacular, la gente ya no se limita a sobrevivir, vive, disfruta de la vida y se empieza a generalizar el interés por el arte, la ecología, la solidaridad, etc., no necesarias para la mera supervivencia. Sin embargo, por otra parte, en esta sociedad red del bienestar empiezan a surgir síntomas alarmantes de apatía y pasividad en los jóvenes y en los no tan jóvenes, crisis de los valores tradicionales, hedonismo, violencia, corrupción, fundamentalismo, terrorismo, etc. ¿Significan estos signos que comenzamos nuestra decadencia y volveremos a repetir la historia? ¿Qué papel le corresponderá a la Orientación psicopedagógica en su función preventiva en este proceso?

Las interrogantes quedan abiertas, y para finalizar este pequeño trabajo, solo se puede añadir que su pretensión es muy humilde, pues estas sencillas líneas solo han intentado activar nuestro pensamiento creativo y motivarnos a reflexionar sobre el futuro de la Orientación psicopedagógica en la sociedad que se avecina.

\section{Bibliografía}

Ainscow, M. (2001). Desarrollo de escuelas inclusivas: ideas, propuestas y experiencias para mejorar las instituciones escolares. Madrid: Edit. Narcea. 


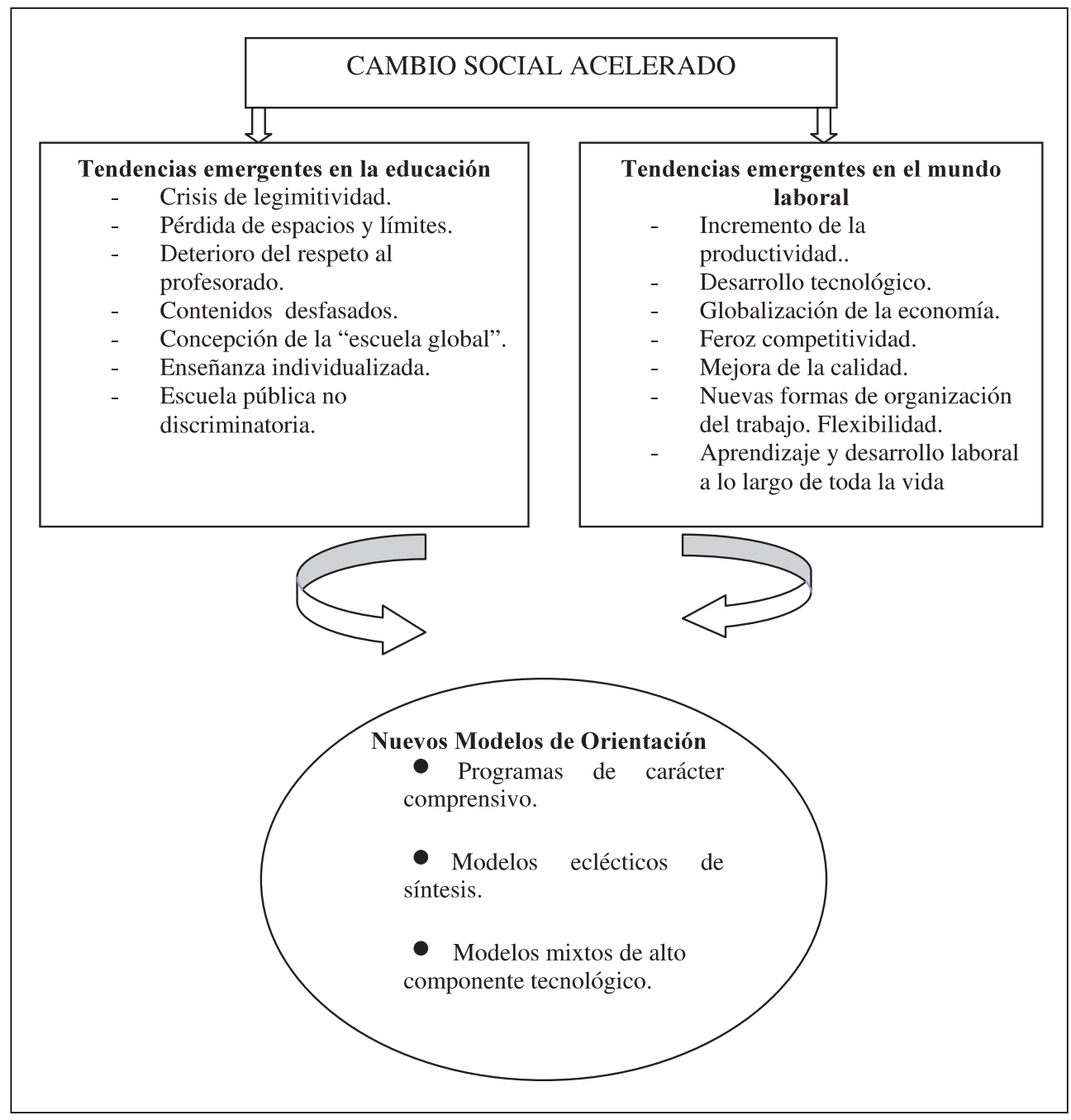

FIGURA 1.

Respuesta de la orientación a la actual encrucijada sociocultural.

Aronowitz, S. et al. (1998). Tecnociencia y cibercultura: La interrelación entre cultura, tecnología y ciencia. Barcelona: Edit. Paidós.

Benavent, J. A. (1992). «Impacto laboral de las nuevas tecnologías: reflexiones para la Orientación Profesional», Revista de Orientación Educativa y Vocacional, 3 (3): 47-58.

Benavent, J. A. (1996). La Orientación Psicopedagógica en España. Vol. I: Desde sus orígenes hasta 1939. Valencia: Promolibro.

Benavent, J. A. (1999). «La Orientación Psicopedagógica en el umbral del s. XXI: Una mirada al futuro». Revista Española de Orientación y Psicopedagogía, 10 (17): 53-62. 
Benavent, J. A. (2000). La Orientación Psicopedagógica en España. Vol. II: Desde 1939 hasta la Ley General de Educación de 1970. Valencia: Promolibro.

Bindé, J. (Coord.). (2002). Claves para el siglo XXI. Barcelona: UNESCO-Edit. Crítica.

Castells, M. (1997 y 1998). La Era de la Información. Economía, Sociedad y Cultura. 3 vol. Madrid: Alianza Editorial S.A.

Delors, J. (1996). La Educación encierra un tesoro. Madrid: Edit. Santillana. - Ediciones UNESCO.

Huxley, A. (1969). Un mundo feliz. Barcelona: Plaza y Janés.

Iaeg. (2002). «The Paris 2001 IAEVG Declaration on Educational and Vocational Guidance». International Journal for Educational and Vocational Guidance, 2 (2): 79-83.

Jiménez, R. A. (1997). «El modelo de consulta. El psicopedagogo como asesor». En R. A. Jiménez y R. Porras (Coords.), Modelos de acción psicopedagógica. Entre el deseo y la realidad. Archidona (Málaga): Ediciones Aljibe: 122-130.

Jouvenel, B. de (1966). El arte de prever el futuro político. Madrid: Edit. Rialp.

Kant, E. (1997). Crítica del juicio. (7 $7^{\mathrm{a}}$ ed.). Madrid: Espasa-Calpe.

Ley 14/1970 de 4 de agosto, General de Educación y financiamiento de la reforma Educativa. (BOE del 6).

Ley Orgánica 1/1990 de 3 de octubre, de Ordenación General del Sistema Educativo. (BOE del 4).

Ley Orgánica 5/2002 de 19 de junio, de las Cualificaciones y de la Formación Profesional. (BOE del 20).

Marchesi, A. (2001). «Presente y futuro de la Reforma Educativa en España». Revista Iberoamericana de Educación, (27):57-76. URL: http://www.campus-oei.org/revista/ (25/06/02).

Marchesi, A. (2002). Controversia en la educación española. Madrid: Alizanza Editorial.

Morin, E. (2002). «¿Qué futuro para la especie humana?». En BINDÉ, J. Claves para el siglo XXI. Barcelona: UNESCO-Edit. Crítica, pp. 64-69.

MEC. (1987). Proyecto para la Reforma de la Enseñanza. Propuesta para el debate. Madrid: Secretaría General Técnica. Servicio de Publicaciones del MEC.

MEC. (1989). Libro Blanco para la Reforma del Sistema Educativo. Madrid: Publicaciones del MEC.

MEC. (1990). La Orientación Educativa y la Intervención Psicopedagógica. Madrid: Publicaciones del MEC.

MECD. (2002). Proyecto de Ley Orgánica de Calidad de la Educación. Aprobado por el Consejo de Ministros en la sesión del 26 de julio de 2002. URL: http://www.mec.es/ (30/07/02).

Nijhof, W. J. (1998). «Qualifying for the Future». En W. J. Nijhof, and J. N. Streumer (Eds,), Key Cualifications in Work and Education. London: Kluwer Academic Publishers: 19-38.

Pimentel, M., Jiménez, A. y Echevarría, M. (Coords.). (2002). España 2010: Mercado laboral. Proyecciones e implicaciones empresariales. Madrid: Watson Wyatt Co.

Quintanal, J. (2002). «La Orientación escolar criterio de calidad». Comunidad Escolar, 20(702):1113. Periódico Digital de Información Educativa. URL: http://comunidad-escolar.pntic.mec.es/ 702/tribuna.html (09/07/02).

Real Academia Española. (1992). Diccionario de la Lengua Española, 2 vol. $21^{\text {a }}$ edi. Madrid: Autor.

Repetto, E. et al. (2002). IAEVG Project: Counsellor Qualification Standarts. URL: http://www.es/ aeop $(02 / 09 / 02)$.

Revista de Educación. (2002). nº 327, monográfico: Educación inclusiva.

Rodríguez Espinar, S. et al. (Coords.).(1993). Teoría y práctica de la Orientación Educativa. Barcelona: PPU. 
Sanz, R. (2001). Orientación psicopedagógica y calidad educativa. Madrid: Edit. Pirámide.

Sófocles. (1959). Edipo Rey. Edipo en Colono. Barcelona: Alma Mater.

Stainbakc, S. y Stainback, W. (1999). Aulas inclusivas. Madrid: Edit. Narcea.

Teilhard de Chardin, P. (1967). El fenómeno humano. $4^{\mathrm{a}}$ ed. Madrid: Taurus.

Toffler, A. (1980). The Third Wave. Trad. al castellano 1984. Barcelona: Plaza y Janés.

Tractenberg, L., Streumer, J. and Van Solingen, S. (2002). «Career Counselling in the Emerging PosIndustrial Society». International Journal for Educational and Vocational Guidance, 2 (2): 85-99.

Urias, F. (2000). «Así viven, así son, así piensan... los jóvenes». El Suplemento Semanal, n 640: 14-27.

Van Esbroeck, R. (2002). «An Introduction to the Paris 2001 IAEVEG Declaration on Educational and Vocational Guidance». International Journal for Educational and Vocational Guidance, 2 (2): 73-78.

Wells, H. G. (1984). La máquina del tiempo. $2^{\mathrm{a}}$ ed. Madrid: Anaya.

Fecha de recepción: 20/04/03

Fecha de revisión: 07/05/03

Fecha de aceptación: 20/05/03 